\title{
Enhanced Charge Transport in 2D Perovskites via Fluorination of Organic Cation
}

\author{
Fei Zhang, ${ }^{\dagger, \# \odot ~ D o n g ~ H o e ~ K i m, ~}{ }^{\dagger, \#}$ Haipeng Lu, ${ }^{\dagger}$ ] Ji-Sang Park, ${ }^{\ddagger}$ Bryon W. Larson, ${ }^{\dagger}$ Jun Hu, ${ }^{\S}$ \\ Liguo Gao, ${ }^{\dagger}$ Chuanxiao Xiao, ${ }^{\dagger}$ Obadiah G. Reid, ${ }^{\dagger, \perp}$ Xihan Chen, ${ }^{\dagger \odot}$ Qian Zhao, ${ }^{\dagger}$ Paul F. Ndione, ${ }^{\dagger}(\bullet$

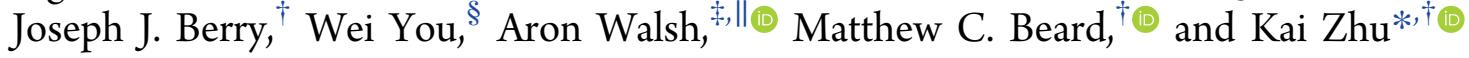 \\ ${ }^{\dagger}$ National Renewable Energy Laboratory, Golden, Colorado 80401, United States \\ ${ }^{\ddagger}$ Department of Materials, Imperial College London, London SW72AZ, United Kingdom \\ ${ }^{\S}$ University of North Carolina at Chapel Hill, Chapel Hill, North Carolina 27599, United States \\ "Department of Materials Science and Engineering, Yonsei University, Seoul 03722, Korea \\ ${ }^{\perp}$ Renewable and Sustainable Energy Institute, University of Colorado Boulder, Boulder, Colorado 80309, United States
}

ABSTRACT: Organic-inorganic halide perovskites incorporating two-dimensional (2D) structures have shown promise for enhancing the stability of perovskite solar cells (PSCs). However, the bulky spacer cations often limit charge transport. Here, we report on a simple approach based on molecular design of the organic spacer to improve the transport properties of $2 \mathrm{D}$ perovskites, and we use phenethylammonium (PEA) as an example. We demonstrate that by fluorine substitution on the para position in PEA to form 4-fluorophenethylammonium (F-PEA), the average phenyl ring centroid-centroid distances in the organic layer become shorter with better aligned stacking of perovskite sheets. The impact is enhanced orbital interactions and charge transport across adjacent inorganic layers as well as increased carrier lifetime and reduced trap density. Using a simple perovskite deposition at room temperature

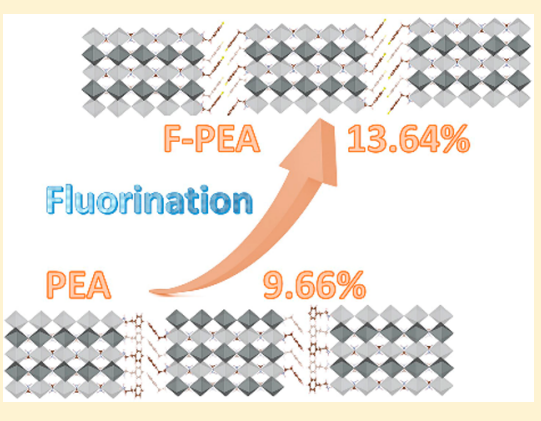
without using any additives, we obtained a power conversion efficiency of $>13 \%$ for (F-PEA) ${ }_{2} \mathrm{MA}_{4} \mathrm{~Pb}_{5} \mathrm{I}_{16}$-based $\mathrm{PSCs}_{\text {. In }}$ addition, the thermal stability of 2D PSCs based on F-PEA is significantly enhanced compared to those based on PEA.

\section{INTRODUCTION}

Three-dimensional (3D) perovskites (e.g., $\mathrm{CH}_{3} \mathrm{NH}_{3} \mathrm{PbI}_{3}$ or $\mathrm{MAPbI}_{3}$ ) were initially reported as a sensitizer for dyesensitized solar cells (DSSCs) with a power conversion efficiency (PCE) of $3.8 \%$ in 2009. ${ }^{1}$ The early pioneering work quickly established the fundamental principles of using 3D perovskites alone as solar cells, i.e., perovskite solar cells (PSCs)..$^{2-4}$ In an astonishing speed, the PCE of PSCs has reached $23.7 \%$ within just 9 years. $^{5-8}$ In addition to the continuous effort to improve cell efficiencies, recent work has been devoted to improving the long-term stability of PSCs against moisture, heat, and light for practical applications. ${ }^{9,10}$ Unlike small cations (e.g., $\mathrm{MA}^{+}$) in $3 \mathrm{D}$ perovskite films, the bulky organic cations in two-dimensional (2D) perovskites (e.g., phenethylammonium $\left(\mathrm{PEA}^{+}\right)$and butylammonium $\left.\left(\mathrm{BA}^{+}\right)\right)$lead to the formation of discrete sheets of lead halide octahedra sandwiched between organic spacer layers. These spacer layers can provide steric hindrance for surface water adsorption in the initial step of decomposition. ${ }^{9}$ The hydrophobic bulky alkylammonium cations in $2 \mathrm{D}$ perovskite lattices can effectively block the accessible pathways of moisture invasion. ${ }^{11}$ The $2 \mathrm{D}$ perovskite is generally described as $\mathrm{M}_{2} \mathrm{~A}_{n-1} \mathrm{~B}_{n} \mathrm{X}_{3 n+1}$, where $\mathrm{M}$ is a large organic cation, such as $\mathrm{BA}$ and PEA; $\mathrm{A}$ is normally methylammonium $\left(\mathrm{MA}^{+}\right)$, formamidinium $\left(\mathrm{FA}^{+}\right)$, or $\mathrm{Cs}^{+} ; \mathrm{B}$ is normally $\mathrm{Pb}^{2+}, \mathrm{Sn}^{2+}$, etc.;
$\mathrm{X}$ is a halide anion, namely, $\mathrm{I}^{-}, \mathrm{Br}^{-}, \mathrm{Cl}^{-}$, etc.; and $n$ is the number of layers of metal halide sheets. Note that in the literature the $n$ values are normally calculated based on the composition of the precursor solutions. Despite improved stability, perovskites with primarily $2 \mathrm{D}$ crystal structures are generally not good options for high-performance solar cells because of their reduced and anisotropic charge transport associated with the bulky organic spacers. ${ }^{9}$

One approach in addressing the transport issue is to lower the ratio of intercalated large cations that form the $2 \mathrm{D}$ perovskite lattice. ${ }^{12,13}$ For example, by optimizing the amount of PEAI into MAI and $\mathrm{PbI}_{2}$ solution, the $n$ value in $\mathrm{PEA}_{2} \mathrm{MA}_{n-1} \mathrm{~Pb}_{n} \mathrm{I}_{3 n+1}$ compounds can in theory be adjusted from 1 to $\infty .{ }^{12}$ Following this strategy, a certified PCE of $15.3 \%$ was achieved with $\mathrm{PEA}_{2} \mathrm{MA}_{n-1} \mathrm{~Pb}_{n} \mathrm{I}_{3 n+1} \quad(n=60){ }^{12}$ However, with a large $n$ value (normally when $n>5$ ), the resulting structure is essentially a $3 \mathrm{D}$ perovskite with a small amount of incorporated $2 \mathrm{D}$ components. ${ }^{9}$ Another approach is to facilitate the preferred vertical growth orientation of the $2 \mathrm{D}$ perovskites by either using additives (e.g., $\mathrm{NH}_{4} \mathrm{SCN}^{14-16}$ $\mathrm{MACl}^{17-19}$ and $\mathrm{NH}_{4} \mathrm{Cl}^{15}$ ) or hot-casting at an elevated deposition temperature, ${ }^{20-23}$ and such approaches have

Received: January 27, 2019

Published: March 18, 2019 

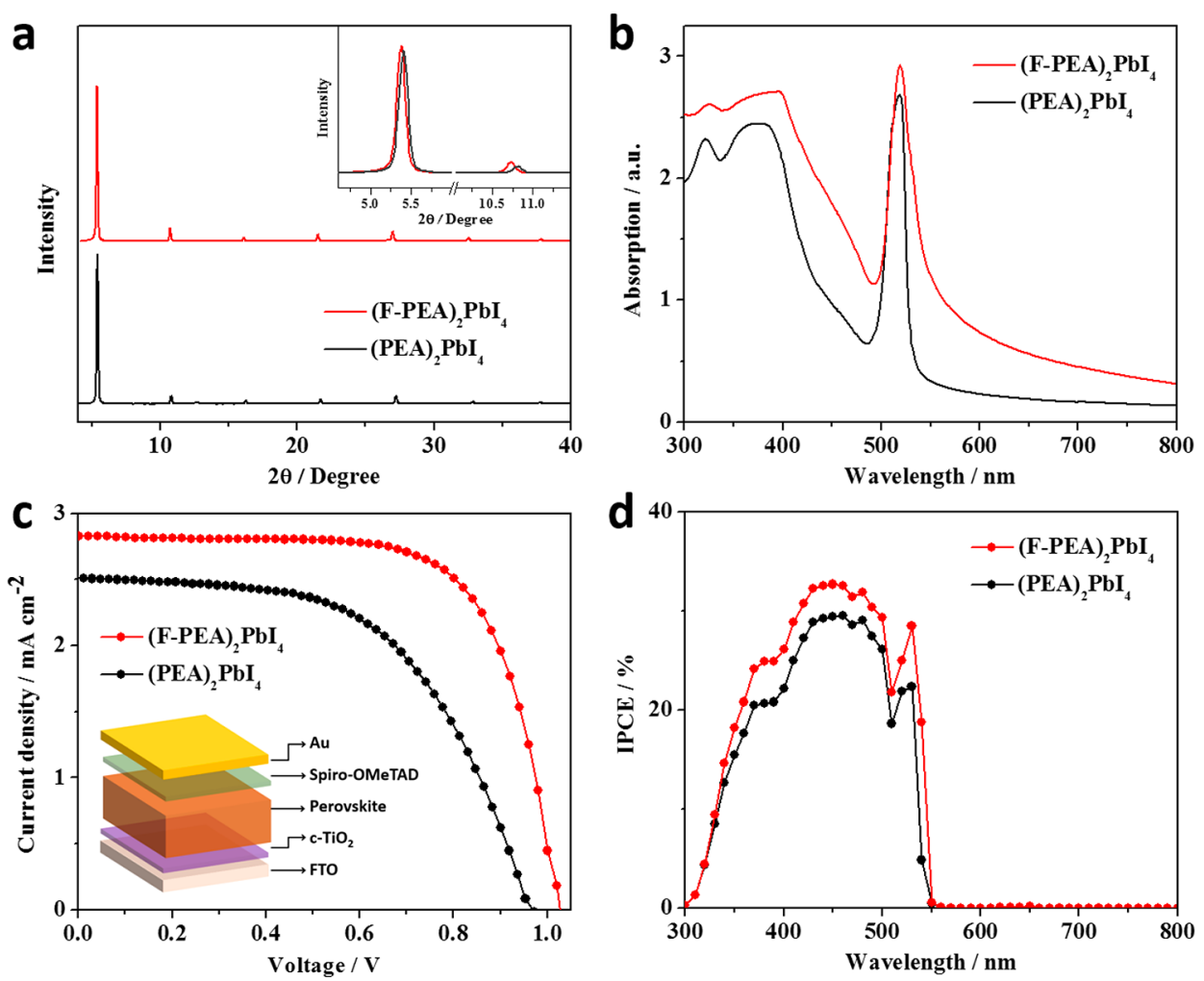

Figure 1. (a) XRD patterns and (b) UV-vis absorption spectra of $n=12 \mathrm{D}(\mathrm{PEA})_{2} \mathrm{PbI}_{4}$ and (F-PEA) ${ }_{2} \mathrm{PbI}_{4}$ perovskite thin films. (c) $J-V$ curves and (d) IPCE spectra of perovskite solar cells based on (PEA) ${ }_{2} \mathrm{PbI}_{4}$ and (F-PEA) ${ }_{2} \mathrm{PbI}_{4}$. The $J-V$ curves were measured with forward scan with a bias step of $10 \mathrm{mV}$.

achieved PCEs greater than $10 \%$. However, for the hot-casting growth, it is difficult to precisely control the substrate temperature during spin-coating; thus, it is not ideal for device reproducibility.

The primary motivation for pursuing a more oriented growth of the $2 \mathrm{D}$ perovskites is to facilitate charge transport/ collection across the $2 \mathrm{D}$ perovskite absorber layer. In this work, we report on a different approach-chemically modifying the bulky organic spacer-to improve the out-ofplane transport. Specifically, we employed 4-fluorophenethylammonium (F-PEA), where the fluorine substitution is on the para position of the phenyl, and we find that the average ring centroid-to-centroid distances in the organic layer are reduced. This enhances the orbital interactions between the inorganic layers, leading to more efficient charge transport across adjacent inorganic layers. This simple F-PEA cation also enhances the stacking alignment of the perovskite sheets, allowing for better interlayer electronic coupling. When using F-PEA in $n=52 \mathrm{D}$ perovskite, i.e., (F-PEA) ${ }_{2} \mathrm{MA}_{4} \mathrm{~Pb}_{5} \mathrm{I}_{16}$ ), the perovskite films exhibit faster charge transport, longer carrier lifetimes, and a lower trap density compared to the PEA-based analogue with no fluorine. As a result, we obtain a PCE > 13\% for (F-PEA) ${ }_{2} \mathrm{MA}_{4} \mathrm{~Pb}_{5} \mathrm{I}_{16}$-based PSCs prepared without using any additives and fabricated at room temperature. These devices also show a better thermal stability than that of $(\mathrm{PEA})_{2} \mathrm{MA}_{4} \mathrm{~Pb}_{5} \mathrm{I}_{16}$. This promising approach provides a simple route for designing 2D PSCs with high efficiency and stability.

\section{RESULT AND DISCUSSION}

Figure 1a shows X-ray diffraction (XRD) patterns of perovskite thin films based on $n=12 \mathrm{D}$ ( $\mathrm{PEA})_{2} \mathrm{PbI}_{4}$ and (F-PEA) ${ }_{2} \mathrm{PbI}_{4}$, with the growth planes primarily parallel to the substrate. ${ }^{24} \mathrm{In}$ comparison to ( $\mathrm{PEA})_{2} \mathrm{PbI}_{4}$, the scattering of X-rays of (F$\mathrm{PEA})_{2} \mathrm{PbI}_{4}$ displays a slight shift toward smaller angles; the inset of Figure la shows the zoom-in view of the first two diffraction peaks. Based on the (002) reflection peaks, the distance between the $2 \mathrm{D}$ perovskite layers is calculated to be 16.41 and $16.35 \AA$ for (F-PEA) $)_{2} \mathrm{PbI}_{4}$ and (PEA) $)_{2} \mathrm{PbI}_{4}$, respectively. The optical ultraviolet-visible (UV-vis) absorption spectra (Figure $1 \mathrm{~b}$ ) are typical of $2 \mathrm{D}$ perovskites, with a high-energy continuum absorption edge and a lower-energy excitonic peak. The slight increase in the absorbance for F-PEA is likely due to increased scattering. To compare how the different organic cations affect the photovoltaic (PV) properties, we fabricated planar PSCs in a configuration of FTO/ compact- $\mathrm{TiO}_{2} /$ perovskite/spiro-OMeTAD/Au. Figure 1c shows the photocurrent density-voltage $(J-V)$ curves of (F$\mathrm{PEA})_{2} \mathrm{PbI}_{4}$ - and (PEA) ${ }_{2} \mathrm{PbI}_{4}$-based PSCs under an AM 1.5G solar simulator. The (PEA) $)_{2} \mathrm{PbI}_{4}$-based PSC gives a $\mathrm{PCE}$ of $1.34 \%$, with a short-circuit current density $\left(J_{\mathrm{sc}}\right)$ of $2.51 \mathrm{~mA}$ $\mathrm{cm}^{-2}$, open-circuit voltage $\left(V_{\mathrm{oc}}\right)$ of $0.97 \mathrm{~V}$, and fill factor $(\mathrm{FF})$ of 0.55 . In contrast, the (F-PEA) $)_{2} \mathrm{PbI}_{4}$-based PSC yields a PCE of $1.90 \%$, with improvements from all $\mathrm{PV}$ parameters $\left(J_{\mathrm{sc}}=\right.$ $2.83 \mathrm{~mA} \mathrm{~cm}^{-2}, V_{\mathrm{oc}}=1.02 \mathrm{~V}$, and $\left.\mathrm{FF}=0.66\right)$; this is among the highest PCE obtained, thus far, for $n=12 \mathrm{D}$ lead-iodide-based PSCs. $^{24}$ Figure 1d shows the incident photon-to-current efficiency (IPCE) spectra, from which the integrated current densities were found to be 2.39 and $2.69 \mathrm{~mA} / \mathrm{cm}^{2}$ for $(\mathrm{PEA})_{2} \mathrm{PbI}_{4}$ and (F-PEA) $)_{2} \mathrm{PbI}_{4}$ PSCs, respectively. Note that the significant $\mathrm{PCE}$ improvement is primarily caused by the increase of FF (by 20\%) when PEA is replaced with F-PEA, which likely results from the differences in charge-transport properties that are discussed in detail below. 

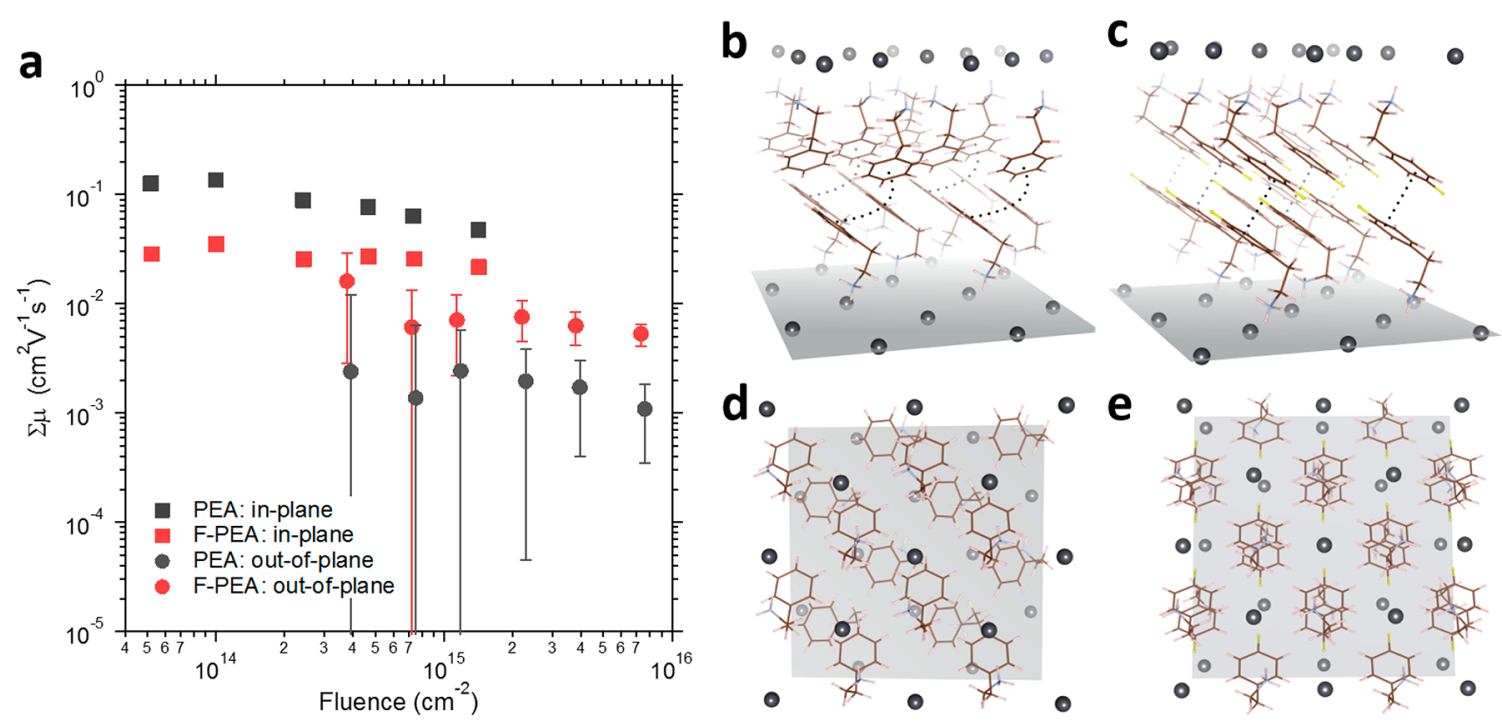

Figure 2. (a) TRMC comparison of out-of-plane and in-plane transport for $n=12 \mathrm{D}$ perovskite thin films. The results are calibrated by the internal quantum yield of charges as discussed in the text. The structures of $(\mathrm{b}, \mathrm{d})(\mathrm{PEA})_{2} \mathrm{PbI}_{4}$ - and (c, e) (F-PEA) ${ }_{2} \mathrm{PbI}_{4}$-based single-crystal XRD. ${ }^{25}$

We use time-resolved microwave conductivity (TRMC) $)^{26,27}$ measurements to compare in-plane and out-of-plane transport in pure $(n=1) 2 \mathrm{D}$ perovskite thin films of $(\mathrm{PEA})_{2} \mathrm{PbI}_{4}$ and $(\mathrm{F}$ $\mathrm{PEA})_{2} \mathrm{PbI}_{4}$. This is achieved using two different microwave cavity configurations that orient the perovskite layers either parallel or perpendicular to the microwave field, while the optical excitation axis remains perpendicular to the film (details given in the Experimental Section in the SI, Figures S1-S3 and Table S1). For $n=12 \mathrm{D}$ perovskite films, the 2D plane is usually parallel to the substrate (Figure 1a; XRD comparison of $n=12 \mathrm{D}$ perovskite thin films).

Figure $2 \mathrm{a}$ shows the $9 \mathrm{GHz}$ mobility extracted from the TRMC data, using the internal quantum yield of charges calculated from the device data in Figure $1 b$,d. Details of this calculation are given in S1. The out-of-plane (or intersheet) microwave mobility of (F-PEA) $)_{2} \mathrm{PbI}_{4}$ is $\sim 7 \times$ larger than that of $(\mathrm{PEA})_{2} \mathrm{PbI}_{4}$. However, based on the $\mathrm{XRD}$ results, the interlayer distance in the F-PEA film appears to be slightly larger than the PEA film, suggesting that the improved out-ofplane conductivity is not simply determined by the interlayer distance, as previously reported. ${ }^{17}$ Figure S4 shows a similar countervailing example, comparing $(\mathrm{BA})_{2} \mathrm{PbI}_{4}$ to $(\mathrm{PEA})_{2} \mathrm{PbI}_{4}$. The layer-to-layer distance for $(\mathrm{BA})_{2} \mathrm{PbI}_{4}$ is notably shorter $(13.76 \AA)$ than $(\mathrm{PEA})_{2} \mathrm{PbI}_{4}(16.35 \AA$ ) $)$, but the out-of-plane mobility is slightly smaller.

This observation is not too surprising if we consider charge transport between inorganic layers as a tunneling process mediated by the organic interlayer. There are two coequal properties of a tunnel junction that control the tunneling probability: distance and barrier height. The latter is more complex and difficult to predict than the former. In this study, the fractional change in interlayer distance between F-PEAand PEA-based 2D structures is small. On the other hand, the differences in barrier height/structure could arise here due to two main effects: (1) a change in the intermolecular electronic coupling between neighboring organic cations and (2) a change in the energetic alignment between the perovskite transport bands and the oxidation or reduction potential of the organic cation. For example, we predict that interlayer hole transport would be optimized when the oxidation potential of the organic cation is resonant with the valence band of the perovskite layer and cations from neighboring layers possess large intermolecular electronic coupling integrals between highest occupied molecular orbitals (HOMOs). At this time, we do not possess any data that allow us to evaluate the question of energetic alignment of the various cations with the perovskite band structure, which will be the focus of future work. However, there is ample structural data in Figure $2 b-e$ to evaluate the likely influence of intermolecular coupling.

Using fluorine substitution to direct and enhance intermolecular packing is a strategy often reported in organic solar cells to enhance PV performance because it enhances mobility as a result of planarization of the polymer/molecular backbone along with better intermolecular order ${ }^{28-30}$ and preferential orientation of the backbone with respect to the discrete donor/acceptor interface. ${ }^{31}$ Here, fluorine substitution in the organic layer also affects the intermolecular packing, as well as the electronic interactions. Figure $2 b-e$ show the side and top views for both samples relative to the $2 \mathrm{D}$ sheets of $\mathrm{PbI}_{6}$ octahedra; only the lead atom centers of the octahedra are shown for clearer visualization of the organic layer. ${ }^{25}$ We have also added a gray plane through one layer of lead atoms for visual reference, which is positioned in the background of the top-view figures. Analysis of the single-crystal XRD data for each structure reveals several key differences. First, the phenyl rings are parallel slip-stacked in the F-PEA structure vs edgeto-face stacked in the PEA structure (Figure 2b,c). The cofacial inter-ring plane distance in the F-PEA sample is $3.588 \AA$, which corresponds to a maximum van der Waals attraction distance for a parallel stacked aromatic dimer. ${ }^{32}$ In the PEA sample with edge-to-face stacking, there are four different closest ring-toring distances that all correspond to the nearest hydrogen atom of an "edge" ring to the centroid of a "face" ring. These values are $3.009,3.050,3.078$, and $3.122 \AA$, suggesting that these are more likely steric interactions rather than electrostatic. For ring centroid-to-centroid distances $\left(R_{\text {cen-cen }}\right)$, there are eight unique nearest-neighbor $R_{\text {cen-cen }}$ values ranging from 4.892 to $6.770 \AA$ in the PEA sample, compared to four unique $R_{\text {cen-cen }}$ values ranging from 3.878 to $6.709 \AA$ in the F-PEA sample. Thus, it is probable that there is enhanced pi-orbital overlap in the out-ofplane direction of the aromatic moieties in F-PEA relative to PEA, which could facilitate more efficient charge transport. ${ }^{33,34}$ 
a $\quad(\text { F-PEA })_{2} \mathrm{MA}_{4} \mathrm{~Pb}_{5} \mathrm{I}_{16}$

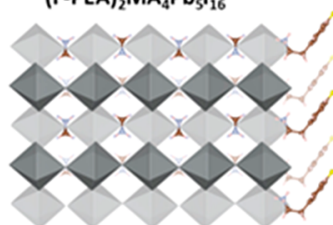

b (PEA) $)_{2} \mathrm{MA}_{4} \mathrm{~Pb}_{5} \mathrm{I}_{16}$

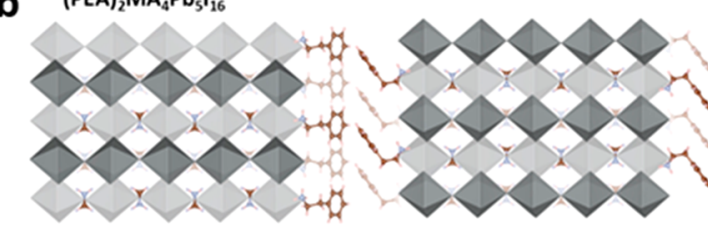

e

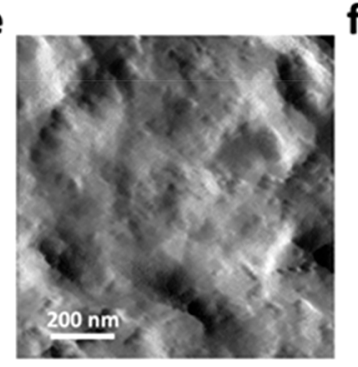

f

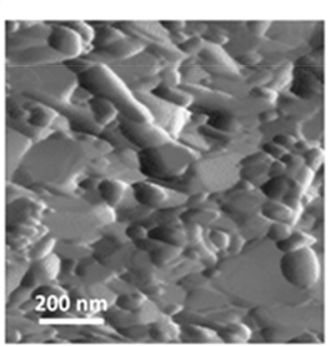

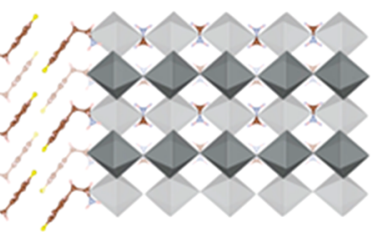
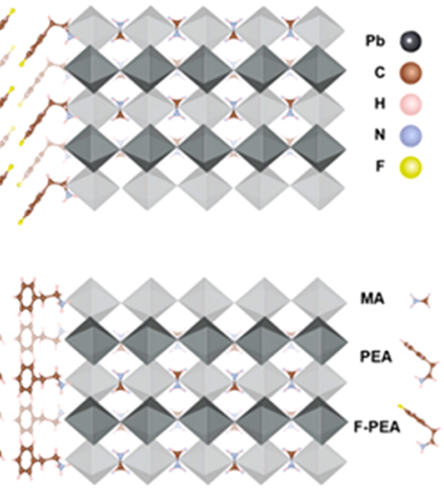

g

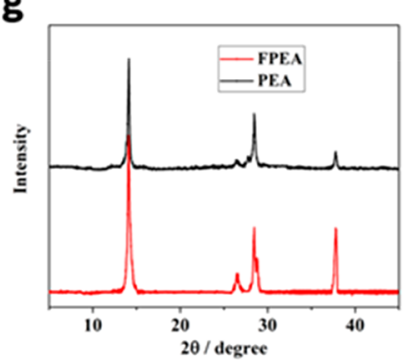

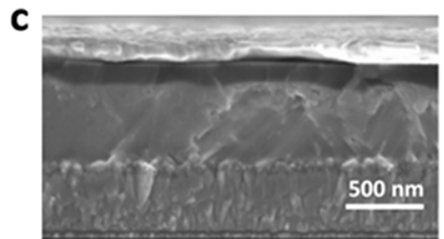

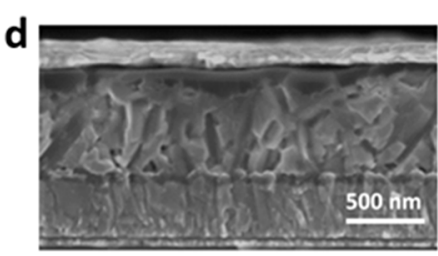

h

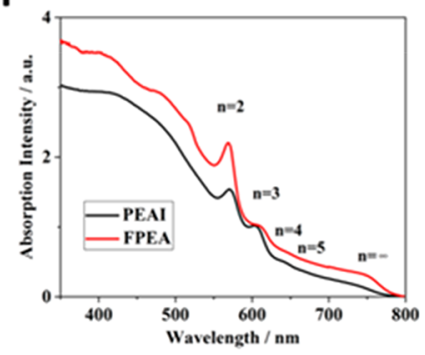

Figure 3. Schematic crystal structures of (a) F-PEA $\mathrm{MA}_{4} \mathrm{~Pb}_{5} \mathrm{I}_{16}$ and (b) $\mathrm{PEA}_{2} \mathrm{MA}_{4} \mathrm{~Pb}_{5} \mathrm{I}_{16}$ perovskites. Structures of $(\mathrm{F}-\mathrm{PEA})_{2} \mathrm{MA}_{4} \mathrm{~Pb} \mathrm{I}_{16}$ or $(\mathrm{PEA})_{2} \mathrm{MA}_{4} \mathrm{~Pb}_{5} \mathrm{I}_{16}$ incorporating five $\left[\mathrm{PbI}_{6}\right]^{4-}$ octahedra $(n=5)$, which share corners along the direction perpendicular to the layers. The individual $\left[\mathrm{Pb}_{5} \mathrm{I}_{16}\right]^{6-}$ slabs are separated by the large organic ligand $\left(\mathrm{F}_{-} \mathrm{PEA}\right)^{2+}$ or $\left(\mathrm{PEA}_{2}\right)^{2+}$. The unit cells of $(\mathrm{F}-\mathrm{PEA})_{2} \mathrm{MA}_{4} \mathrm{~Pb}_{5} \mathrm{I}_{16}$ and $\left(\mathrm{PEA}_{2} \mathrm{MA}_{4} \mathrm{~Pb}_{5} \mathrm{I}_{16}\right.$ are constructed based on single-crystal diffraction structure analysis of $n=12 \mathrm{D}$ perovskites $(\mathrm{F}-\mathrm{PEA})_{2} \mathrm{PbI}_{4}$ and $(\mathrm{PEA})_{2} \mathrm{PbI}_{4}$, respectively. ${ }^{25}$ Crosssectional scanning electron microscopy (SEM) images (scale is $500 \mathrm{~nm}$ ) of (c) (F-PEA) ${ }_{2} \mathrm{MA}_{4} \mathrm{~Pb}_{5} \mathrm{I}_{16}$ - and (d) $(\mathrm{PEA})_{2} \mathrm{MA}_{4} \mathrm{~Pb}_{5} \mathrm{I}_{16}$-based perovskite solar cells. AFM tapping mode of perovskite thin films based on (e) $\mathrm{PEA}_{2} \mathrm{MA}_{4} \mathrm{~Pb}_{5} \mathrm{I}_{16}$ and (f) (F-PEA) ${ }_{2} \mathrm{MA}_{4} \mathrm{~Pb}_{5} \mathrm{I}_{16}$. (g) XRD patterns and (h) UVvis absorption spectra of perovskite thin films based on $\mathrm{PEA}_{2} \mathrm{MA}_{4} \mathrm{~Pb}_{5} \mathrm{I}_{16}$ (black line) and (F-PEA) ${ }_{2} \mathrm{MA}_{4} \mathrm{~Pb}_{5} \mathrm{I}_{16}$ (red line).

The different arrangements of the PEA and F-PEA molecules were also confirmed by density functional theory calculations (Figure S5). To find out which arrangement the molecules prefer, we calculated how much the energy changes from molecular edge-to-face stacking to the parallel arrangement. The energy change $\left(\Delta E_{\mathrm{f}}\right)$ was obtained with and without dispersion correction to check the effect of the van der Waals interaction. PEA molecular layers prefer to be stacked edge-to-face regardless of the inclusion of the dispersion correction (Table S2). F-PEA molecules, on the other hand, are calculated to be stacked in parallel $\left(\Delta E_{f}=-0.05 \mathrm{eV} / \mathrm{f}\right.$.u. when the dispersion interactions are included. The edge-toface stacking is slightly favored $\left(\Delta E_{f}=0.01 \mathrm{eV} / \mathrm{f}\right.$.u. $)$ in the absence of long-range interactions. This result confirms that the van der Waals interaction promotes the parallel arrangement of phenyl rings. We expect that one arrangement will be dominant for each material because of the noticeable energy difference between the two arrangements.

It is noteworthy that the sheet-to-sheet position of lead octahedra centers are also different between the two samples. The PEA molecules are oriented edge-to-face, so the coordinating ammonium groups are also offset relative to each other at the top and bottom of the organic layer, meaning that the $\mathrm{Pb}$ centers also end up staggered in alternating sheets (refer to the lead atom and $\mathrm{NH}_{3}$ positions in the top views of Figure $2 \mathrm{~d}, \mathrm{e})$. In the F-PEA sample, the rings are parallel slip stacked and offset relative to the plane of the lead atoms, allowing the ammonium groups to be approximately eclipsed in the vertical direction; hence, the lead atoms are also in an eclipsed orientation between sheets. It appears that the simple fluorination of PEA cations (i.e., F-PEA) aligns the stacking of perovskite sheets and allows for a better interlayer electronic coupling, which is better for charge transfer. ${ }^{35,36}$ As such, we attribute the enhanced out-of-plane conductivity in the F-PEA sample to the preferred molecular stacking in both organic (reduced ring-to-ring distance) and inorganic phases (aligned $\mathrm{PbI}_{6}$ sheets). Interestingly, according to the in-plane vs out-ofplane TRMC results for the $n=12 \mathrm{D}$ samples, the nonsubstituted PEA sample exhibits a higher in-plane carrier mobility. We hypothesize that the in-plane mobility is more heavily determined by the $\mathrm{Pb}$ planes rather than the organic layer. ${ }^{36}$ The average $\mathrm{Pb}-\mathrm{I}-\mathrm{Pb}$ angle of (F-PEA) ${ }_{2} \mathrm{PbI}_{4}$ $\left(152.98^{\circ}\right)$ is smaller than that of $(\mathrm{PEA})_{2} \mathrm{PbI}_{4}\left(153.30^{\circ}\right)$, which will lead to a reduced mobility. ${ }^{36}$

We further extended our comparison study to $n=52 \mathrm{D}$ perovskites using PEA and F-PEA. Two-dimensional perovskites with $n=4$ or 5 have recently received increasing attention as potential candidates for achieving high stability as well as high efficiency for solar cells. ${ }^{12,37}$ Figure $3 a, b$ displays schematic crystal structures of (F-PEA) ${ }_{2} \mathrm{MA}_{4} \mathrm{~Pb}_{5} \mathrm{I}_{16}$ and $\mathrm{PEA}_{2} \mathrm{MA}_{4} \mathrm{~Pb}_{5} \mathrm{I}_{16}$. F-PEA (or PEA)-based $n=52 \mathrm{D}$ perovskite films were prepared from precursor solutions consisting of $\mathrm{PbI}_{2}$, F-PEAI (or PEAI), and $\mathrm{CH}_{3} \mathrm{NH}_{3} \mathrm{I}$ (MAI) at a stoichiometric ratio of 5:2:4 in dimethylformamide (DMF) and dimethyl sulfoxide (DMSO) with a concentration of 1.25 $\mathrm{mol} / \mathrm{L}$. The coating process was done in air, and detailed procedures are given in SI. We investigated the surface morphology of 2D perovskite films by scanning electron microscopy (SEM) and atomic force microscopy (AFM) (Figures $3 \mathrm{c}-\mathrm{f}$ and $\mathrm{S} 6$ ). Both films appear uniform, the presenting surface morphology of (F-PEA) ${ }_{2} \mathrm{MA}_{4} \mathrm{~Pb}_{5} \mathrm{I}_{16}$ has larger structures than that of the $(\mathrm{PEA})_{2} \mathrm{MA}_{4} \mathrm{~Pb}_{5} \mathrm{I}_{16}$ film, and 
a

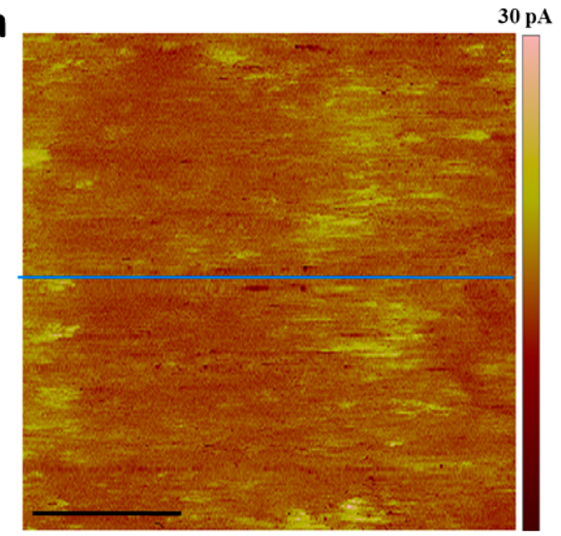

C
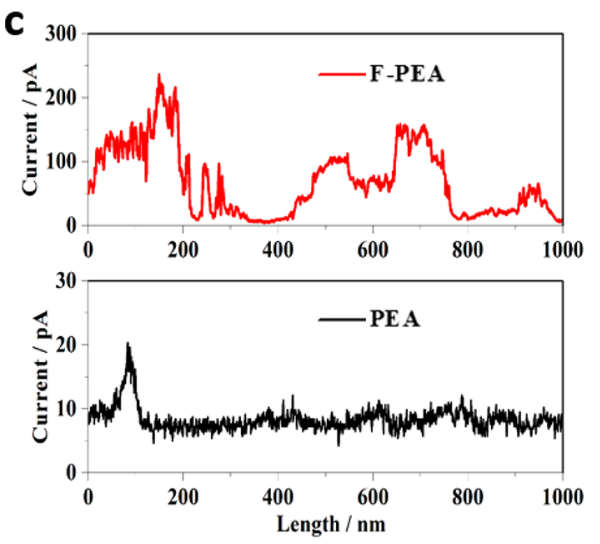

b

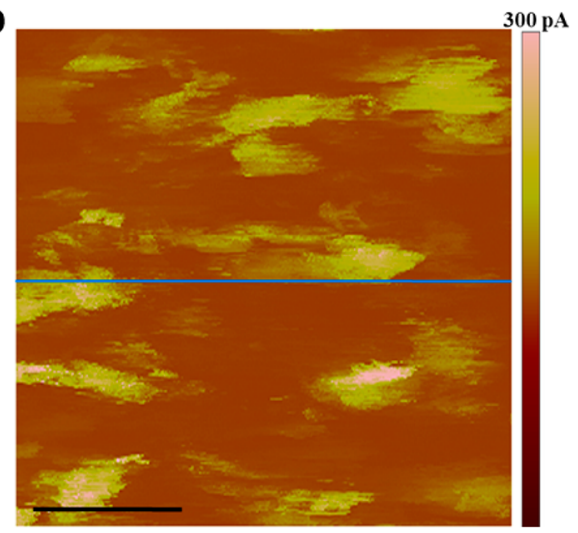

d

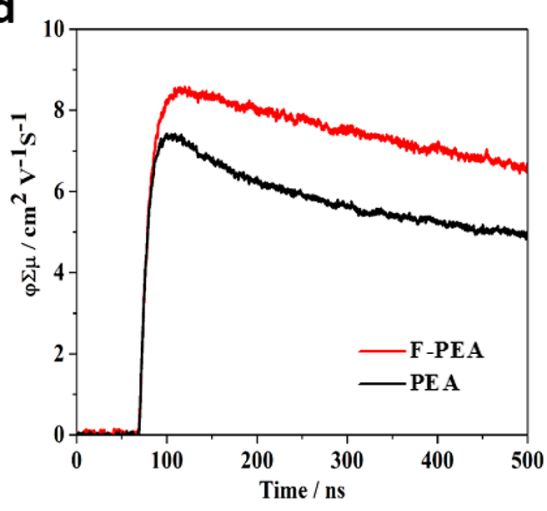

Figure 4. C-AFM mapping images for the $n=52 \mathrm{D}$ perovskite films based on (a) PEA and (b) F-PEA obtained at a bias voltage of $1 \mathrm{~V}$ in the dark. The scale bar is $300 \mathrm{~nm}$. (c) Line profiles of current mapping of the corresponding perovskite films. (d) Typical photoconductivity $(\varphi \Sigma \mu)$ transient for the corresponding perovskite films.

the (F-PEA $)_{2} \mathrm{MA}_{4} \mathrm{~Pb}_{5} \mathrm{I}_{16}$ film clearly presents a more homogeneous cross-section consistent with fewer internal boundaries. XRD patterns (Figure $3 \mathrm{~g}$ ) exhibit similar, strong, and sharp perovskite characteristic peaks. The intensity of the (F-PEA) ${ }_{2} \mathrm{MA}_{4} \mathrm{~Pb}_{5} \mathrm{I}_{16}$ perovskite film at the (110) peak becomes stronger and the full width at half-maximum (fwhm, $0.26^{\circ}$ ) decreased when compared with the $(\mathrm{PEA})_{2} \mathrm{MA}_{4} \mathrm{~Pb}_{5} \mathrm{I}_{16}$ perovskite films $\left(0.29^{\circ}\right)$. Although determination of grain size is difficult for this class of materials, these data indicate that the reduced fwhm is consistent with the morphology changes viewed in the SEM/AFM. UV-vis absorption spectra (Figure $3 \mathrm{~h}$ ) of (F-PEA) ${ }_{2} \mathrm{MA}_{4} \mathrm{~Pb}_{5} \mathrm{I}_{16}$ and (PEA) ${ }_{2} \mathrm{MA}_{4} \mathrm{~Pb}_{5} \mathrm{I}_{16}$ films display various excitonic peaks associated with different $n$ values, which are consistent with previous reports. ${ }^{4-19}$

To examine the impact of fluorination of PEA on the optoelectronic properties in $n=52 \mathrm{D}$ perovskites, we carried out a set of characterizations including conductive atomic force microscopy (C-AFM), TRMC, and time-resolved photoluminescence (TRPL). As shown in Figure 4a,b, the $(\mathrm{PEA})_{2} \mathrm{MA}_{4} \mathrm{~Pb}_{5} \mathrm{I}_{16}$ sample shows relatively low current signal, which indicates poor electrical conductivity of the perovskite films. In contrast, the (F-PEA) ${ }_{2} \mathrm{MA}_{4} \mathrm{~Pb}_{5} \mathrm{I}_{16}$ sample displays a significantly increased (about 10-fold) current signal, which suggests better carrier conduction. This drastic difference is further illustrated in the line-profile comparison of the C-AFM results (Figure 4c). Note that significant nonuniformity exists (different parts of the film show different amounts of current generation), which could be attributed to $2 \mathrm{D}$ phases containing different $n$ values as indicated by the optical absorption (Figure $3 \mathrm{~h}$ ).
Figure $4 \mathrm{~d}$ compares the typical TRMC transients with 640 $\mathrm{nm}$ laser excitation at an intensity near $1 \times 10^{10} \mathrm{~cm}^{-2}$ absorbed photon flux. The carrier generation yield is about unity for $n=$ $52 \mathrm{D}$ PSCs in this study, so the yield-mobility product $\varphi \Sigma \mu$ value can be seen as a measure of the carrier mobility. Analysis of these TRMC results yields a peak value of $\sim 7 \mathrm{~cm}^{2} \mathrm{~V}^{-1} \mathrm{~s}^{-1}$ for the (PEA) ${ }_{2} \mathrm{MA}_{4} \mathrm{~Pb}_{5} \mathrm{I}_{16}$ films and a higher value of $\sim 9 \mathrm{~cm}^{2}$ $\mathrm{V}^{-1} \mathrm{~s}^{-1}$ for (F-PEA) ${ }_{2} \mathrm{MA}_{4} \mathrm{~Pb}_{5} \mathrm{I}_{16}$. TRPL measurements ${ }^{38,39}$ (Figure S7) show carrier lifetimes of about 20 and $30 \mathrm{~ns}$ for the (PEA) ${ }_{2} \mathrm{MA}_{4} \mathrm{~Pb}_{5} \mathrm{I}_{16}$ and (F-PEA) ${ }_{2} \mathrm{MA}_{4} \mathrm{~Pb}_{5} \mathrm{I}_{16}$ films, respectively. TRPL carrier lifetimes of several nanoseconds are characteristic for layered organic-inorganic perovskites. ${ }^{40,41}$ The improved carrier mobility and lifetime further confirm that the fluorine substitution can enhance charge transport and suppress recombination. ${ }^{42-44}$ The improved photophysical properties are also consistent with a reduced dark carrier density ${ }^{26}\left(n_{\mathrm{d}}=\right.$ $6.4 \times 10^{16} \mathrm{~cm}^{-3}$ ) for the (F-PEA) ${ }_{2} \mathrm{MA}_{4} \mathrm{~Pb}_{5} \mathrm{I}_{16}$ sample compared to the $(\mathrm{PEA})_{2} \mathrm{MA}_{4} \mathrm{~Pb}_{5} \mathrm{I}_{16}$ sample $\left(n_{\mathrm{d}}=9.5 \times 10^{16}\right.$ $\left.\mathrm{cm}^{-3}\right)$, as shown in Figure S8.

On the basis of this collection of data, we anticipate that the improved structural and corresponding optoelectronic properties of the (F-PEA) $)_{2} \mathrm{MA}_{4} \mathrm{~Pb}_{5} \mathrm{I}_{16}$ should contribute to the enhanced PCE in the corresponding PSCs. To test this hypothesis, we compared how the $2 \mathrm{D}$ cations affect the PV properties of PSCs based on $n=52 \mathrm{D}$ perovskites. Figure 5a shows the $J-V$ curves of (F-PEA) ${ }_{2} \mathrm{MA}_{4} \mathrm{~Pb}_{5} \mathrm{I}_{16^{-}}$and $(\mathrm{PEA})_{2} \mathrm{MA}_{4} \mathrm{~Pb}_{5} \mathrm{I}_{16}$-based PSCs under simulated AM $1.5 \mathrm{G}$ one-sun illumination. The corresponding PV parameters are summarized in Table S3. The device based on $(\mathrm{PEA})_{2} \mathrm{MA}_{4} \mathrm{~Pb}_{5} \mathrm{I}_{16}$ perovskite gives a $\mathrm{PCE}$ of $9.66 \%$, with a 

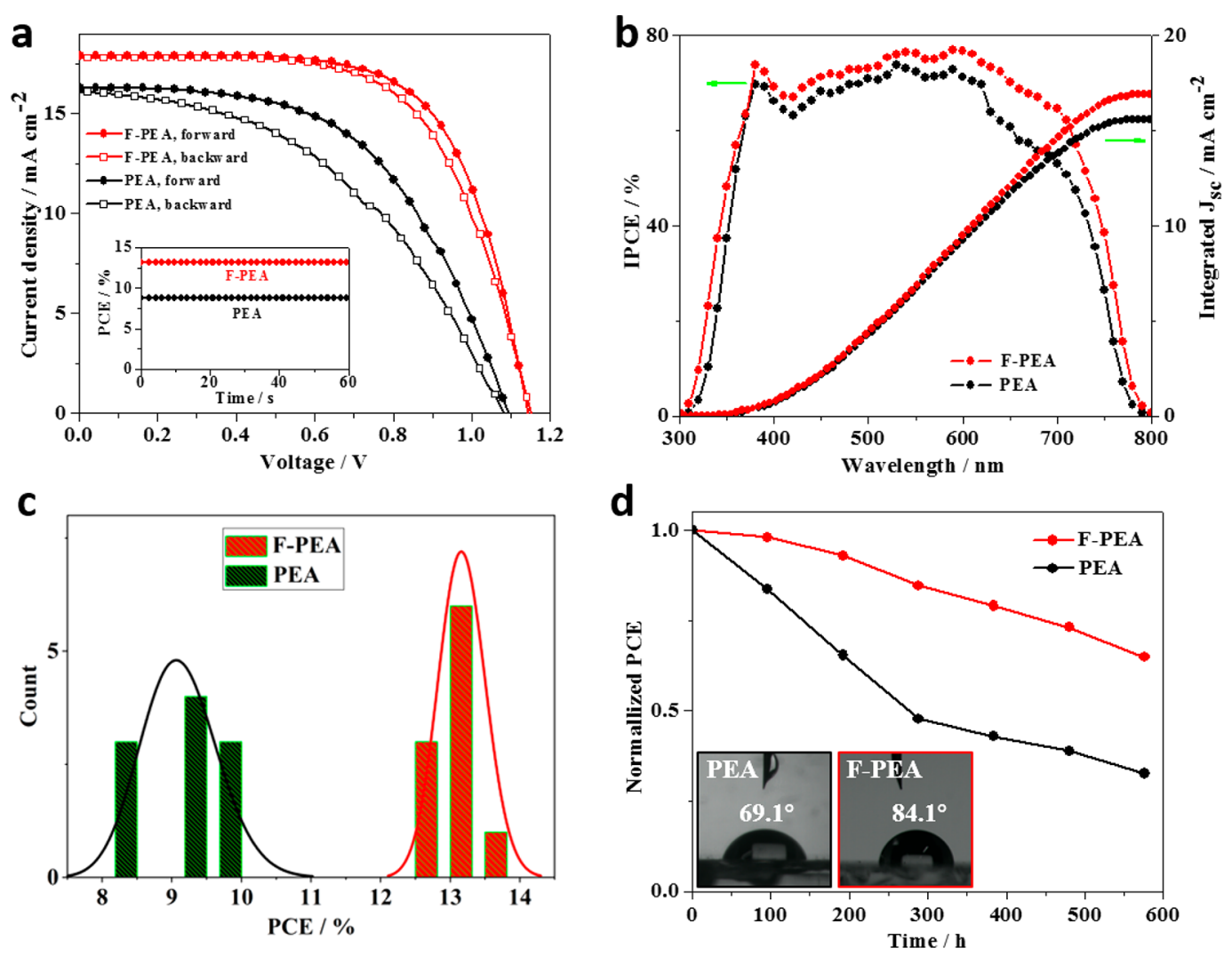

Figure 5. (a) $J-V$ curves of PSCs based on $n=52 \mathrm{D}(\mathrm{PEA})_{2} \mathrm{MA}_{4} \mathrm{~Pb}_{5} \mathrm{I}_{16}$ and (F-PEA) ${ }_{2} \mathrm{MA}_{4} \mathrm{~Pb}_{5} \mathrm{I}_{16}$ films with a bias step of $10 \mathrm{mV}$. Inset shows the stabilized power output of the corresponding devices. (b) IPCE spectra and integrated current curves of the corresponding devices. (c) Reproducibility of PSCs based on the corresponding films. (d) Thermal stability comparison of PEA- and F-PEA-based PSCs tested at $70{ }^{\circ} \mathrm{C}$ in ambient environment, dark storage, without any encapsulation. Inset shows the contact angles between corresponding perovskite films and water.

$J_{\mathrm{sc}}$ of $16.27 \mathrm{~mA} \mathrm{~cm}{ }^{-2}, V_{\mathrm{oc}}$ of $1.10 \mathrm{~V}$, and $\mathrm{FF}$ of 0.54 . For $(\mathrm{F}-$ PEA) ${ }_{2} \mathrm{MA}_{4} \mathrm{~Pb}_{5} \mathrm{I}_{16}$-based PSCs, the PCE is further improved to $13.64 \%$, with a $J_{\mathrm{sc}}$ of $17.86 \mathrm{~mA} \mathrm{~cm} \mathrm{~cm}^{-2}, V_{\mathrm{oc}}$ of $1.14 \mathrm{~V}$, and $\mathrm{FF}$ of 0.67. This is among the highest PCEs in comparison with recent reports, as shown in Table $\mathrm{S} 4$. We ascribe the improved PCE (especially the enhanced FF) with the (FPEA $)_{2} \mathrm{MA}_{4} \mathrm{~Pb}_{5} \mathrm{I}_{16}$ perovskite thin films primarily to the improved charge transport and reduced trap density. ${ }^{45,46}$ In addition, the PCE is also consistent with that obtained from the stabilized power output measurements (inset of Figure 5a), and $J_{s c}$ is matched with the integrated current densities estimated from the IPCE spectra (Figure $5 b$ ). In addition to the improved PCE, the hysteresis (the difference in the PCEs from the reversed-scan and the forward-scan $J-V$ curves) is also significantly reduced for PSCs based on F-PEA, which can be attributed to the improved perovskite film quality (e.g., larger grain size, lower defect density, higher carrier mobility). ${ }^{44,47,48}$ The statistical PCE data of the PSCs based on (F-PEA) ${ }_{2} \mathrm{MA}_{4} \mathrm{~Pb}_{5} \mathrm{I}_{16}$ and (PEA) ${ }_{2} \mathrm{MA}_{4} \mathrm{~Pb}_{5} \mathrm{I}_{16}$ thin films are shown in Figure $5 \mathrm{c}$.

Thermal stability tests under an ambient environment at 70 ${ }^{\circ} \mathrm{C}$ for PEA- and F-PEA-based PSCs without encapsulation were also conducted. As shown in Figure 5d, the unencapsulated (F-PEA) ${ }_{2} \mathrm{MA}_{4} \mathrm{~Pb}_{5} \mathrm{I}_{16}$-based devices maintained $65 \%$ of their initial PCE after $576 \mathrm{~h}$; under the same conditions, the measured PCEs decreased to $32 \%$ of their initial values for (PEA) ${ }_{2} \mathrm{MA}_{4} \mathrm{~Pb}_{5} \mathrm{I}_{16}$-based PSCs. The enhanced stability of (F$\mathrm{PEA})_{2} \mathrm{MA}_{4} \mathrm{~Pb}_{5} \mathrm{I}_{16}$-based PSCs can also be seen from Figure $\mathrm{S} 9$. The color of (F-PEA) ${ }_{2} \mathrm{MA}_{4} \mathrm{~Pb}_{5} \mathrm{I}_{16}$-based solar cells remains persistent, whereas those of $(\mathrm{PEA})_{2} \mathrm{MA}_{4} \mathrm{~Pb}_{5} \mathrm{I}_{16}$-based solar cells turned almost transparent. The improved environmental stability of the F-PEA-based 2D perovskites is consistent with the better hydrophobicity by fluorination (Figure $5 \mathrm{~d}$ inset), lower trap densities, and stronger interaction between interlayers. $^{8,35,43,46,49-51}$

In summary, we report a simple approach of modifying PEA with fluorine to get 4-fluorophenethylammonium (F-PEA) and applied it in 2D perovskite solar cells. The F-PEA sample displays enhanced out-of-plane conductivity owing to the preferred molecular stacking in both organic (reduced ring-toring distance) and inorganic phases (aligned $\mathrm{PbI}_{6}$ sheets). FPEA-based $2 \mathrm{D}$ perovskite ((F-PEA) $\left.{ }_{2} \mathrm{MA}_{n-1} \mathrm{~Pb}_{n} \mathrm{I}_{3 n+1}, n=5\right)$ exhibited better charge transport and lower trap density than materials based on PEA. A solar cell PCE > 13\% was obtained based on (F-PEA) ${ }_{2} \mathrm{MA}_{4} \mathrm{~Pb}_{5} \mathrm{I}_{15}$, which is higher than that of PEA. This was achieved without using any additives or heated substrate to help the growth of $2 \mathrm{D}$ perovskites. In addition, the devices based on F-PEA also displayed better stability than that based on PEA after $576 \mathrm{~h}$ under $70{ }^{\circ} \mathrm{C}$ in an ambient environment. This promising approach provides a simple route for designing 2D PSCs with high efficiency and stability.

\section{ASSOCIATED CONTENT}

\section{S Supporting Information}

The Supporting Information is available free of charge on the ACS Publications website at DOI: 10.1021/jacs.9b00972.

Experimental section and methods details, atomistic models by DFT calculations, SEM images, normalized TRPL spectra, DMC measurement, figures of devices 
before and after aging, summary of PV performance from the past three years, energy change by DFT calculations, and $J-V$ data (PDF)

\section{AUTHOR INFORMATION}

\section{Corresponding Author}

*kai.zhu@nrel.gov

\section{ORCID $\odot$}

Fei Zhang: 0000-0002-3774-9520

Haipeng Lu: 0000-0003-0252-3086

Liguo Gao: 0000-0002-5390-3663

Xihan Chen: 0000-0001-7907-2549

Paul F. Ndione: 0000-0003-4444-2938

Aron Walsh: 0000-0001-5460-7033

Matthew C. Beard: 0000-0002-2711-1355

Kai Zhu: 0000-0003-0908-3909

\section{Author Contributions}

${ }^{\#}$ F. Zhang and D. H. Kim contributed equally.

\section{Notes}

The authors declare no competing financial interest.

\section{ACKNOWLEDGMENTS}

The work was supported by the U.S. Department of Energy under Contract No. DE-AC36-08GO28308 with Alliance for Sustainable Energy, Limited Liability Company (LLC), the Manager and Operator of the National Renewable Energy Laboratory. We acknowledge the support of perovskite synthesis and device fabrication/characterization, and microwave cavity modeling and characterization from the Derisking Halide Perovskite Solar Cells program of the National Center for Photovoltaics, funded by the U.S. Department of Energy, Office of Energy Efficiency and Renewable Energy, Solar Energy Technologies Office; the support of the in-plane and out-of-plane transport measurement and analysis from the Center for Hybrid Organic Inorganic Semiconductors for Energy (CHOISE), an Energy Frontier Research Center funded by the Office of Basic Energy Sciences, Office of Science within the U.S. Department of Energy; and the support of density functional theory calculations by supercomputer time awarded through PRACE on the Swiss National Supercomputing Centre (CSCS) under project pr51. The views expressed in the article do not necessarily represent the views of the DOE or the U.S. Government.

\section{REFERENCES}

(1) Kojima, A.; Teshima, K.; Shirai, Y.; Miyasaka, T. Organometal Halide Perovskites as Visible-Light Sensitizers for Photovoltaic Cells. J. Am. Chem. Soc. 2009, 131, 6050-6051.

(2) Liu, M.; Johnston, M. B.; Snaith, H. J. Efficient Planar Heterojunction Perovskite Solar Cells by Vapour Deposition. Nature 2013, 501, 395-398.

(3) Kim, H.-S.; Lee, C.-R.; Im, J.-H.; Lee, K.-B.; Moehl, T.; Marchioro, A.; Moon, S.-J.; Humphry-Baker, R.; Yum, J.-H.; Moser, J. E.; Grätzel, M.; Park, N.-G. Lead Iodide Perovskite Sensitized AllSolid-State Submicron Thin Film Mesoscopic Solar Cell with Efficiency Exceeding 9\%. Sci. Rep. 2012, 2, 1-7.

(4) Burschka, J.; Pellet, N.; Moon, S.-J.; Humphry-Baker, R.; Gao, P.; Nazeeruddin, M. K.; Grätzel, M. Sequential Deposition as a Route to High-Performance Perovskite-Sensitized Solar Cells. Nature 2013, 499, 316-319.

(5) NREL. Best Research-Cell Efficiencies, http://www.nrel.gov/ncpv/ images/efficiency_chart.jpg. (October 2018).
(6) Bi, D.; Yi, C.; Luo, J.; Decoppet, J.-D.; Zhang, F.; Zakeeruddin, S. M.; Li, X.; Hagfeldt, A.; Grätzel, M. Polymer-Templated Nucleation and Crystal Growth of Perovskite Films for Solar Cells with Efficiency Greater than 21\%. Nat. Energy 2016, 1, 16142.

(7) Zhang, F.; Shi, W.; Luo, J.; Pellet, N.; Yi, C.; Li, X.; Zhao, X.; Dennis, T. J. S.; Li, X.; Wang, S.; Xiao, Y.; Zakeeruddin, S. M.; Bi, D.; Grätzel, M. Isomer-Pure Bis-PCBM-Assisted Crystal Engineering of Perovskite Solar Cells Showing Excellent Efficiency and Stability. Adv. Mater. 2017, 29, 1606806.

(8) Zhang, F.; Bi, D. Q.; Pellet, N.; Xiao, C. X.; Li, Z.; Berry, J. J.; Zakeeruddin, S. M.; Zhu, K.; Grätzel, M. Suppressing Defects Through Synergistic Effect of Lewis Base and Lewis Acid for Highly Efficient and Stable Perovskite Solar Cells. Energy Environ. Sci. 2018, 11, 3480-3490.

(9) Zhang, F.; Kim, D. H.; Zhu, K. 3D/2D Multidimensional Perovskites: Balance of High Performance and Stability for Perovskite Solar Cells. Current Opinion in Electrochemistry 2018, 11, 105-113.

(10) Correa-Baena, J. P.; Saliba, M.; Buonassisi, T.; Gratzel, M.; Abate, A.; Tress, W.; Hagfeldt, A. Promises and Challenges of Perovskite Solar Cells. Science 2017, 358, 739-744.

(11) Yang, S.; Wang, Y.; Liu, P.; Cheng, Y.-B.; Zhao, H. J.; Yang, H. G. Functionalization of Perovskite Thin Films with Moisture-Tolerant Molecules. Nat. Energy 2016, 1, 15016.

(12) Quan, L. N.; Yuan, M.; Comin, R.; Voznyy, O.; Beauregard, E. M.; Hoogland, S.; Buin, A.; Kirmani, A. R.; Zhao, K.; Amassian, A.; Kim, D. H.; Sargent, E. H. Ligand-Stabilized Reduced-Dimensionality Perovskites. J. Am. Chem. Soc. 2016, 138, 2649-2655.

(13) Proppe, A. H.; Quintero-Bermudez, R.; Tan, H.; Voznyy, O.; Kelley, S. O.; Sargent, E. H. Synthetic Control over Quantum Well Width Distribution and Carrier Migration in Low-Dimensional Perovskite Photovoltaics. J. Am. Chem. Soc. 2018, 140, 2890-2896.

(14) Zhang, X. Q.; Wu, G.; Fu, W. W.; Qin, M. C.; Yang, W. T.; Yan, J. L.; Zhang, Z. Q.; Lu, X. H.; Chen, H. Z. Orientation Regulation of Phenylethylammonium Cation Based 2D Perovskite Solar Cell with Efficiency Higher Than 11\%. Adv. Energy Mater. 2018, 8, 1702498.

(15) Fu, W. F.; Wang, J.; Zuo, L. J.; Gao, K.; Liu, F.; Ginger, D. S.; Jen, A. K.-Y. Two-Dimensional Perovskite Solar Cells with $14.1 \%$ Power Conversion Efficiency and $0.68 \%$ External Radiative Efficiency. ACS Energy Lett. 2018, 3, 2086-2093.

(16) Zhang, X.; Wu, G.; Yang, S.; Fu, W.; Zhang, Z.; Chen, C.; Liu, W.; Yan, J.; Yang, W.; Chen, H. Vertically Oriented 2D Layered Perovskite Solar Cells with Enhanced Efficiency and Good Stability. Small 2017, 13, 1700611.

(17) Ma, C. Q.; Shen, D.; Ng, T.-W.; Lo, M. F.; Lee, C. S. 2D Perovskites with Short Interlayer Distance for High-Performance Solar Cell Application. Adv. Mater. 2018, 30, 1800710.

(18) Lai, H. T.; Kan, B.; Liu, T. T.; Zheng, N.; Xie, Z. Q.; Zhou, T.; Wan, X. J.; Zhang, X. D.; Liu, Y. S.; Chen, Y. S. Two-Dimensional Ruddlesden-Popper Perovskite with Nanorod-like Morphology for Solar Cells with Efficiency Exceeding 15\%. J. Am. Chem. Soc. 2018, 140, 11639-11646.

(19) Qing, J.; Liu, X. K.; Li, M.; Liu, F.; Yuan, Z.; Tiukalova, E.; Yan, Z.; Duchamp, M.; Chen, S.; Wang, Y. M.; Bai, S.; Liu, J. M.; Snaith, H. J.; Lee, C.-S.; Sum, T. C.; Gao, F. Aligned and Graded Type- II Ruddlesden-Popper Perovskite Films for Efficient Solar Cells. Adv. Energy Mater. 2018, 8, 1800185.

(20) Tsai, H.; Nie, W.; Blancon, J. C.; Stoumpos, C. C.; Asadpour, R.; Harutyunyan, B.; Neukirch, A. J.; Verduzco, R.; Crochet, J. J.; Tretiak, S.; Pedesseau, L.; Even, J.; Alam, M. A.; Gupta, G.; Lou, J.; Ajayan, P. M.; Bedzyk, M. J.; Kanatzidis, M. G. High-Efficiency TwoDimensional Ruddlesden-Popper Perovskite Solar Cells. Nature 2016, 536, 312-316.

(21) Zhang, X.; Ren, X.; Liu, B.; Munir, R.; Zhu, X.; Yang, D.; Li, J.; Liu, Y.; Smilgies, D.-M.; Li, R.; Yang, Z.; Niu, T.; Wang, X.; Amassian, A.; Zhao, K.; Liu, S. Stable High Efficiency Two-Dimensional Perovskite Solar Cells via Cesium Doping. Energy Environ. Sci. 2017, 10, 2095-2102.

(22) Yan, L.; Hu, J.; Guo, Z. K.; Chen, H.; Toney, M. F.; Moran, A. M.; You, W. General Post-Annealing Method Enables High-Efficiency 
Two-Dimensional Perovskite Solar Cells. ACS Appl. Mater. Interfaces 2018, 10, 33187-33197.

(23) Cheng, P. R.; Xu, Z.; Li, J. B.; Liu, Y. C.; Fan, Y. Y.; Yu, L. Y.; Smilgies, D. M.; Müller, C.; Zhao, K.; Liu, S. Z. F. Highly Efficient Ruddlesden-Popper Halide Perovskite $\mathrm{PA}_{2} \mathrm{MA}_{4} \mathrm{~Pb}_{5} \mathrm{I}_{16}$ Solar Cells. ACS Energy Lett. 2018, 3, 1975-1982.

(24) Febriansyah, B.; Koh, T. M.; Lekina, Y.; Jamaludin, N. F.; Bruno, A. B.; Ganguly, R.; Shen, Z. X.; Mhaisalkar, S. G.; England, J. Improved Photovoltaic Efficiency and Amplified Photocurrent Generation in Mesoporous $\mathrm{n}=12 \mathrm{D}$ Lead-Iodide Perovskite Solar Cells. Chem. Mater. 2019, 31, 890-898.

(25) Kikuchi, K.; Takeoka, Y.; Rikukawa, M.; Sanui, K. Structure and Optical Properties of Lead Iodide Based Two-Dimensional Perovskite Compounds Containing Fluorophenethylamines. Current Applied Physics. 2004, 4, 599-602.

(26) Reid, O. G.; Moore, D. T.; Li, Z.; Zhao, D.; Yan, Y.; Zhu, K.; Rumbles, G. Quantitative Analysis of Time-Resolved Microwave Conductivity Data. J. Phys. D: Appl. Phys. 2017, 50, 493002.

(27) Savenije, T. J.; Ferguson, A. J.; Kopidakis, N.; Rumbles, G. Revealing the Dynamics of Charge Carriers in Polymer: Fullerene Blends Using Photoinduced Time-Resolved Microwave Conductivity. J. Phys. Chem. C 2013, 117, 24085-24103.

(28) Carsten, B.; Szarko, J. M.; Son, H. J.; Wang, W.; Lu, L.; He, F.; Rolczynski, B. S.; Lou, S. J.; Chen, L. X.; Yu, L. Examining the Effect of the Dipole Moment on Charge Separation in Donor-Acceptor Polymers for Organic Photovoltaic Applications. J. Am. Chem. Soc. 2011, 133, 20468-20475.

(29) Schroeder, B. C.; Huang, Z.; Ashraf, R. S.; Smith, J.; DAngelo, P.; Watkins, S. E.; Anthopoulos, T. D.; Durrant, J. R.; McCulloch, I. Silaindacenodithiophene-Based Low Band Gap Polymers-The Effect of Fluorine Substitution on Device Performances and Film Morphologies. Adv. Funct. Mater. 2012, 22, 1663-1670.

(30) Zhang, Q. Q.; Kelly, M. A.; Bauer, N.; You, W. The Curious Case of Fluorination of Conjugated Polymers for Solar Cells. Acc. Chem. Res. 2017, 50, 2401-2409.

(31) Tumbleston, J. R.; Collins, B. A.; Yang, L.; Stuart, A. C.; Gann, E.; Ma, W.; You, W.; Ade, H. The Influence of Molecular Orientation on Organic Bulk Heterojunction Solar Cells. Nat. Photonics 2014, 8, $385-391$.

(32) http://www.jbc.org/content/273/25/15458.full.pdf.

(33) Mas-Torrent, M.; Hadley, P.; Bromley, S. T.; Ribas, X.; Tarrés, J.; Mas, M.; Molins, E.; Veciana, J.; Rovira, C. Correlation between Crystal Structure and Mobility in Organic Field-Effect Transistors Based on Single Crystals of Tetrathiafulvalene Derivatives. J. Am. Chem. Soc. 2004, 126, 8546-8553.

(34) Coropceanu, V.; Cornil, J.; da Silva, D. A.; Olivier, Y.; Silbey, R.; Bredas, J. L. Charge Transport in Organic Semiconductors. Chem. Rev. 2007, 107, 926-952.

(35) Mao, L.; Ke, W.; Pedesseau, L.; Wu, Y.; Katan, C.; Even, J.; Wasielewski, M. R.; Stoumpos, C. C.; Kanatzidis, M. G. Hybrid Dion-Jacobson 2D Lead Iodide Perovskites. J. Am. Chem. Soc. 2018, 140, 3775-3783.

(36) Mao, L.; Stoumpos, C. C.; Kanatzidis, M. G. Two-Dimensional Hybrid Halide Perovskites: Principles and Promises. J. Am. Chem. Soc. 2019, 141, 1171-1190.

(37) Mitzi, D. B.; Feild, C. A.; Harrison, T. A.; Guloy, A. M. Conducting Tin Halides with a Layered Organic-Based Perovskite Structure. Nature 1994, 369, 467-469.

(38) Yang, B.; Chen, J.; Hong, F.; Mao, X.; Zheng, K.; Yang, S.; Li, Y.; Pullerits, T.; Deng, W.; Han, K. Lead-Free, Air-Stable AllInorganic Cesium Bismuth Halide Perovskite Nanocrystals. Angew. Chem., Int. Ed. 2017, 56, 12471-12475.

(39) Yang, B.; Chen, J.; Yang, S.; Hong, F.; Sun, L.; Han, P.; Pullerits, T.; Deng, W.; Han, K. Lead-Free Silver-Bismuth Halide Double Perovskite Nanocrystal. Angew. Chem., Int. Ed. 2018, 57, $5359-5363$.

(40) Dohner, E. R.; Jaffe, A.; Bradshaw, L. R.; Karunadasa, H. I. Intrinsic White-Light Emission from Layered Hybrid Perovskites. J. Am. Chem. Soc. 2014, 136, 13154-13157.
(41) Kitazawa, N.; Watanabe, Y. Optical Properties of Natural Quantum-Well Compounds $\left(\mathrm{C}_{6} \mathrm{H}_{5}-\mathrm{C}_{\mathrm{n}} \mathrm{H}_{2 \mathrm{n}}-\mathrm{NH}_{3}\right)_{2} \mathrm{PbBr}_{4}(\mathrm{n}=1-4)$. J. Phys. Chem. Solids 2010, 71, 797-802.

(42) Zheng, K.; Chen, Y.; Sun, Y.; Chen, J.; Chábera, P.; Schaller, R.; Al-Marri, M. J.; Canton, S. E.; Liang, Z.; Pullerits, T. Inter-Phase Charge and Energy Transfer in Ruddlesden-Popper 2D Perovskites: Critical Role of the Spacing Cations. J. Mater. Chem. A 2018, 6, 6244-6250.

(43) Zhu, H.; Zhang, F.; Xiao, Y.; Wang, S.; Li, X. Suppressing Defects Through Thiadiazole Derivatives that Modulate $\mathrm{CH}_{3} \mathrm{NH}_{3} \mathrm{PbI}_{3}$ Crystal Growth for Highly Stable Perovskite Solar Cells under Dark Conditions. J. Mater. Chem. A 2018, 6, 4971-4980.

(44) Yuan, Y.; Huang, J. S. Ion Migration in Organometal Trihalide Perovskite and Its Impact on Photovoltaic Efficiency and Stability. Acc. Chem. Res. 2016, 49, 286-293.

(45) Chen, Y. N.; Sun, Y. Y.; Peng, J. J.; Tang, J. H.; Zheng, K. B.; Liang, Z. Q. 2D Ruddlesden-Popper Perovskites for Optoelectronics. Adv. Mater. 2018, 30, 1703487.

(46) Frost, J. M.; Butler, K. T.; Brivio, F.; Hendon, C. H.; van Schilfgaarde, M.; Walsh, A. Atomistic Origins of High-Performance in Hybrid Halide Perovskite Solar Cells. Nano Lett. 2014, 14, 25842590.

(47) Sun, M.; Zhang, F.; Liu, H.; Li, X.; Xiao, Y.; Wang, S. Tuning the Crystal Growth of Perovskite Thin-Films by Adding the 2pyridylthiourea Additive for Highly Efficient and Stable Solar Cells Prepared in Ambient Air. J. Mater. Chem. A 2017, 5, 13448-13456.

(48) Zhao, H.; Wang, S.; Sun, M.; Zhang, F.; Li, X.; Xiao, Y. Enhanced Stability and Optoelectronic Properties of $\mathrm{MAPbI}_{3}$ Films with Cationic Surface Active Agent for Perovskite Solar Cells. J. Mater. Chem. A 2018, 6, 10825-10834.

(49) Zhang, F.; Wang, S.; Zhu, H.; Liu, X.; Liu, H.; Li, X.; Xiao, Y.; Zakeeruddin, S. M.; Grätzel, M. Impact of Peripheral Groups on Phenothiazine-Based Hole-Transporting Materials for Perovskite Solar Cells. ACS Energy Lett. 2018, 3, 1145-1152.

(50) Guo, J. J.; Bai, Z. C.; Meng, X. F.; Sun, M. M.; Song, J. H.; Shen, Z. S.; Ma, N.; Chen, Z. L.; Zhang, F. Novel Dopant-Free Metallophthalocyanines Based Hole Transporting Materials for Perovskite Solar Cells: The Effect of Core Metal on Photovoltaic Performance. Sol. Energy 2017, 155, 121-129.

(51) Zhang, F.; Wang, Z. Q.; Zhu, H. W.; Pellet, N.-P.; Luo, J. S.; Yi, C. Y.; Liu, X. C.; Liu, H. L.; Wang, S. R.; Li, X. G.; Xiao, Y.; Zakeeruddin, S. M.; Bi, D. Q.; Grätzel, M. Over 20\% PCE Perovskite Solar Cells with Superior Stability Achieved by Novel and Low-Cost Hole-Transporting Materials. Nano Energy 2017, 41, 469-475. 